\title{
Investigating the impact of intellectual capital on organizational performance: A case study in an Iranian medical science university
}

\author{
Mojtaba Rafiei ${ }^{1,2 \star}$, Hady Ghaffari ${ }^{1}$ and Roshanak Parsapur ${ }^{3}$ \\ ${ }^{1}$ Markazi State Payam-e-noor University (PNU), Iran. \\ ${ }^{2}$ Assistant professor in Markazi State Payam e noor, Iran. \\ ${ }^{3}$ Tehran State Payam-e-noor University (PNU), Iran.
}

Accepted 15 September, 2011

\begin{abstract}
New economic growth comes from information and knowledge. This situation increases importance of intellectual capital as an economic and research item. The role of intellectual capital in improvement of performance and social and technological economy is the subject of new researches in knowledge organizations. Intellectual capital is known as the main source of competitive advantage and value creation in today's organizations. In this research, at the first stage, intellectual capital and its elements studied in a library study and sub items of this capitals is determined. In the second stage of the research, two main hypotheses and seven sub-hypotheses in the field of intellectual capital and the relationship between the components of intellectual capital and performance in some Iranian hospitals were considered. Then, the hypotheses were examined and analyzed by SPSS software. The statistic society of this research was of all directors, deputies, administrative and financial managers of Kermanshah University of Medical Sciences. The questionnaire was distributed between 195 persons that had been selected randomly from static society. Obtained data were analyzed by regression and correlation techniques. The outcomes showed that there are some correlations between intellectual capital, s components and performance.
\end{abstract}

Key words: Intellectual capital, performance, human capital, structural capital, hospital.

\section{INTRODUCTION}

Scientists and researchers in different courses such as Sociology, Economy, and Management believe that some basic fundamental movements have occurred in societies and countries. These movements (knowledge and learning) are the bases and axes of changes (Davenport, 1998). Related strategic knowledge and concepts are considered as the main principle and component to survive the organization and to keep its competitive position (Alam et al., 2010). Mack Alveri believes that knowledge and knowledge employees are key principles of organization to gain sustainable development, and are

*Corresponding author. E-mail: m_rafiei@pnu.ac.ir. Tel: 00989188640802. the major future competitive sources of organization. The extant literature further affirms that the firm's competitive advantage and performance are largely influenced by its intellectual capital (Tovstiga and Tulugurova, 2009). Moreover, Marr (2000) claims that knowledge management is a definite necessity for benefit and flexibility of private and public organizations. So, knowing and understanding its circumstances of relating to other organization sources and assets is one of the duties of managers and executers. On the other hand, intellectual capital, among other things, has a major effect on the circumstances of using other organizational sources. In the absence of intellectual capital, other organizational sources and capitals lose their effectiveness and gaining development and progress in the organization becomes difficult. 
Intellectual capital can create a new cognition of economic-intellectual system either at the level of macroeconomics or management of organizations and institutions and help managers in guiding the. system (Alam and Hoque, 2010). Determining and identifying the components and indicators of intellectual capital assets and evaluation of these issues is one of the most important challenges of these days' organizations. Measuring intellectual capital includes issues like rate, growth assets such as ideas, innovations, and creativities which are associated with different fields of knowledge and are not considered as assets by traditional accounting standards and tools. Meanwhile, in modern evaluating system, these assets affect market value of an institution. This matter can be seen in comparison between developed countries and developing ones, because development and progress cannot only be justified based on tangible assets. In many cases, high rates of investments have information-base and knowledge-base infrastructures.

\section{Knowledge-based economy}

Information economy, virtual economy, net economy, digital economy and recently, knowledge-based economy, are titles which refer to Organization for Economic Co-operation and Development (OECD). In any form and title, knowledge-based economy is an economy in which production and exploitation of knowledge plays a key role in economic growth and wealth creation. In other words, the agricultural economy, labor and natural resources, and in the industrial economy, capital, machinery and management are the main factors of economic growth. In knowledge-based economy, science and technology and entrepreneurship will be the key factors. In other words, knowledge-based economy is directly based on acquisition, creation, distribution and use of knowledge in all economic activities. Knowledge as data, processes, systems and output is considered to be a strategic resource that causes an increasing efficiency for the whole body of economics and economic (Alam et al., 2010). Thus, success factors of economies and businesses depend on the aggregation of these factors and the exploitation of knowledge. This means that knowledge-based economy is based on human resources and manpower, and manpower is considered as the greatest wealth of any country (Alam et al., 2010). Although the traditional factors of production, such as labor, capital, raw materials and entrepreneurship still remains, knowledge is considered as the key driving growth and creates new values and the basis for maintaining competitive position. Information technology is a tool of basic enabling, but the core of informationbased economy is human capital, especially the capacity of creation, innovation, production and exploitation of new ideas and also utilizing technology and performing entrepreneurship skills (Fard, 2007). These types of economies are manifested in economic trends of OECD and leads toward the investments of the high-level technologies, industries based on high technology, highly skilled workforce and associated productivity benefits. Although knowledge as important factors in economic growth has a long history, now, economists are trying to find a way to inject knowledge and technology directly to their theories and models. New growth theory shows the attempts to understand the role of knowledge and technology to promote productivity and economic growth (Alam et al., 2010). In this view, investments in research and development, formal education and application and new management structures are key factors. In addition to investing in knowledge, distributing knowledge through formal and informal networks for economic function is something essential (Alam and Khalifa, 2009). Knowledge is increasing, moulding and transforming data from day to day through computers, and information networks in the information society. Implicit knowledge (including knowledge and application of skills used by molding) is essential in knowledge-based economy because it emphasizes on the importance of continuous learning by individuals and companies. In knowledge-based economy, innovation through the interaction between producers and users in the exchange of molded and implicit knowledge is achieved.

This innovation model replaced the traditional linear model. Formation of national innovation systems, which is the combination of flows and relationships among industry, government and academic centers in science and technology develop-ment, is an important economic factor in knowledge-based economies (Alam and Khalifa, 2007).

\section{Different concepts and ideas about intellectual capital}

Intellectual capital is one of the concepts in the era of knowledge-based economy, which is used to draw attention to the intangible assets.

According to some experts, describing intellectual capital is easier than its scientific definition. Because those who research in the field of intellectual capital, by reviewing others definitions and adding some words (playing with words), have attempted to present specific definition to the social science. They do not understand that their definition is being defined only by the conditions and environment of their research and it can not be generalized to all organizations in the world. Although all these definitions can be considered correct, it must be careful that intellectual capital is a concept of a multidisciplinary, so its understanding is definitely different from one area to other ones. As Chatzkel says, all definitions of the structure are valid and it is left for the users to select the best definition to fix some of the problems of their work 
environment (Chatzkel, 2003). Terms that are somewhat parallel with the structures of the intellectual capital include knowledge management, learning organization, intangible assets, intangible income, organizational learning and others.

If it may not be hyperbole and exaggeration; the intellectual capital can be considered as an umbrella that includes all these equivalent words (Zahedi and Lotfizadeh, 2007; Marr and Moustaghfir, 2005). OECD (1999) defines the intellectual capital as a two-category economic value of intangible organizational assets, such as human and structure. In this definition, humans can be customers, employees, suppliers, competitors and government officials.

Some researchers believe intellectual capital refers to collecting intangible resources and flows of them (Bontis, 1999). Bontis believes that the intellectual capital components, by influencing each other, identify the flow and direction of value creation of the company. Brooking knows the difference between book value and market value of the companies resulting from intellectual capital (Brooking, 1997).

Edvinsson and Malone (1997) knows intellectual capital as a source of intangible assets or hidden one that are not often reflected on the balance sheet. According to Harrison and Sullivan (2000), intellectual capital refers to knowledge that has the potential to become a profit and an advantage.

Intellectual capital includes a lot of organizational values, such as profitability, strategic position (market share, goodwill, and excelled in leadership, reputation and fame), gaining innovation of other companies, customer loyalty, reduction of costs, and improvement of productivity.

From the viewpoint of Roos and Roos (1997), the total knowledge of organization members and practical interpreters consider intellectual capital as one type of knowledge applied to cases such as trademarks, patents and trademark rights.

Stewart (1999) believes that intellectual materials such as knowledge, information, intellectual property and experience that they can be used for wealth creation are called intellectual capital.

From management view, intellectual capital refers to knowledge, experience, application, technology, organizational relationships and professional skills that will bring competitive advantage for the company in the market (Stewart, 1997). This definition will scrutinize people who form the organization, organizational structure dimensions and all organizational communications.

Generally, intellectual capital can be defined as follows: Lev (2001) believes that the terminology of knowledge assets, intangible assets and intellectual capital are used in particular areas. For example, intangible assets are used in the field of accounting, knowledge assets are used in economics and intellectual capital are used in business management courses.

\section{Distinction between intangible assets and intellectual capital}

On intangible assets and intellectual capital, about seven views can be seen in the subject literature. In the first view, intangible assets and intellectual capital can be divided into components. Researchers divide intellectual capital to many components as follows: Brooking's (1997) classifications (market assets, spiritual property, human assets and infrastructural assets); Edvinsson and Malone (1997) (human, structural, customer, and organizational capital, and innovation and processes); Lev (2001) (intangibles related to innovation, human resources, and structural ones); Marr and Moustaghfir (2005) (stakeholder knowledge assets and structural ones); Organization for economic co-operation and development (structural and human capital); and Asoybay (employees' competence, internal structure and external structure), all are parts of this perspective. In the second view, intangible assets and intellectual capital can be divided into different levels. Terms such as generating intangibles and capable of being commercial productive and also potential intellectual capital and identified ones are considered in this view. In the third perspective, intangible assets and intellectual capital can be used as synonym. Brooking, Lev et al. and Mayo's definitions are included in this view. In the fourth viewpoint, intellectual capital is a subset of intangible assets. Bontis et al. (2000) definitions are placed here. In the fifth view, intangible assets are a subset of intellectual assets. In the sixth point of view, intellectual capital is a liability issue, not an asset issue. Definitions and explanations by Edvisson and Malone are considered here. Finally, the term intellectual capital is the economic value of intangible assets.

\section{Components of intellectual capital}

The majority of classifications that are formed from intellectual capital have been on agreement about three aspects like human capital, structural capital and customer capital and some scientist believe that central to components of intellectual capital, is human capital, which denotes what a single employee brings into the value adding processes and encompasses professional competence, social competence, employee motivation, and leadership ability (Halim, 2010). Sometimes structural capital is divided into three categories of process capital, spiritual property, innovation capital (Chatzkel, 2002).

\section{Human capital}

The first category of the classification of intellectual capital is human capital. In particular, human capital 
represents stored knowledge in the collective ability of the company to extract the best solutions from within the minds of individual employees (Bontis et al., 2000). Edvinsson and Malone (1997) define human capital as knowledge, skill, innovation, and the cumulative ability of individual participants to resolve the ongoing work. Also, in their opinion, human capital includes values, culture and philosophy of the company. Stewart (1997) defines the human capital as capabilities of those who are references of innovation and modernization in the organization. All definitions of human capital can be placed in the following three approaches: Economic costs - exchange theory, human capital theory and resourceoriented perspective to the organization. First, economic costs - exchange theory assumes that these companies are in search of hiring people in the best possible way. While hiring people as employers, companies can get people from the inside of the company (by the way of education and promotion) and those outside of the company (with spending education expenditure) to provide humanitarian needs of its organization. Certainly, companies choose the best matter with a cost comparison of both methods. Totally, human capital theory in this area should have a special double feature of assets and uncertainty (unknown) of assets. Second, human capital theory emphasizes the fact that corporate decisions about the amount or rate of investment in humans should be made by comparing current costs with the benefits (for example, improved production control) of investments in the future. Here, human capital refers to provided technical training staff. Thus, the human capital theory should have dual characteristics of specialized skills and incomparability of transfer (non-transmission). Finally, resource-oriented viewpoint claims that skills which are the point of gravity of the competitive advantage of companies must develop with internal development and acquired public technology through outsourcing. The main characteristics of these core skills include value, rarity, and non-imitative.

\section{Structural capital}

The second category of the classification of intellectual capital is structural capital. Structural capital includes all deposits of non-human knowledge in organizations. Chen et al. (2004) believe that structural capital refers to the system, structure, current business practices of an organization. To make it clear, structural capital can be crystallized as a cultural organization. Organizational culture consists of values, beliefs, and norms of behavior that are shared and accepted by all staff of organization. Of an organization view, values are the most important thing for business, employees and customers. Beliefs refer to the employees' attitudes toward themselves, organization and customers. Also, behavioral norms are unwritten rules that have stressed on issues such as the appearance of the staff and their cooperation with each other. Organizational culture is a valuable asset under the guidance of a philosophy of good management. Only through a strong organizational culture, a company can expose its staff's competencies to the public view, and motivate them to serve their organization and customers willingly. Structural capital is a function of human capital because human capital is considered as a determining factor in the form of an organization. On the other hand, structural capital as soon as it is influenced under the human capital, is created openly and fully independent of human capital (Bontis and Richardson, 2000).

\section{Consumer capital}

The third category of the classification of intellectual capital is customer capital or communicational capital. Customer capital includes both the present value of organization relationships with customers and the potential value of organizations originated from this relationship in the future. Therefore, the essence of the customer capital lies in hidden knowledge of marketing and communication channels that an organization will design during the birth period (Bontis et al., 2000). Customer capital represents the potential that the company has for intangible items outside of the organizations. In fact, customer capital includes the external dimensions of the organizations' income process. Trading, reputation, strategic alliances, networks, communication with customers and suppliers, all have income potential. Generally, customer capital that acts as a bridge in intellectual capital, is the main determining factor in converting the intellectual capital to market value, consequently it is the function of business organization. Without customer capital, market value or the function of business organizations can not be achieved. Therefore, the growth of customer capital depends on the support by human capital and structural capital (Chen et al., 2004)

\section{Organizational performance}

The purpose of organizational function is such as the leadership and eminent in the industry; vision and future prospects, gaining profit with regard to the other, growth and increase of profits, the growth of services, efficiency of assets after the deduction of tax, the rate of success in launching new services, the overall response or reaction to competitiveness, performance and overall success, and service efficiency after the deduction of tax.

\section{Research purposes}

This research will generally follow two operational and 
theoretical objectives as follows: operational objectives, which include identifying intellectual capital and their constituent elements. The other research objective is helping the managers make decisions about intellectual capital, such as, which one of these funds should be paid more attention and be kept, and provide guidelines for policy on intellectual capital. The theoretical goals of this research are to fill the existing vacuum in this area. It is expected that the function of this research provides the space to develop future studies to identify and evaluate intellectual capital in the public sector. On the other hand, according to the spread of globalization, the fade out of geographical borders and expansion of electronic communications, these capitals become very important. One of the objectives of this study is to show the importance of matter to the relevant organizations and institutions. The most important goals of this study can be summarized as follows:

1. Analysis of the relationship between intellectual capital components together.

2. Determining the relationship between intellectual capital and function of hospitals.

3. Information about status (relative and qualitative) of components of intellectual capital in hospitals.

\section{RESEARCH HYPOTHESES}

First major hypothesis: The triple components of intellectual capital have a positive and meaningful effect the performance of hospital.

First subsidiary hypothesis: There is a significant positive relationship between the level of human capital in the hospitals and their performance.

Second subsidiary hypothesis: There is a significant positive relationship between the level of structural capital in the hospitals and their performance.

Third subsidiary hypothesis: There is a significant positive relationship between the level of customer capital in the hospitals and their performance.

Fourth subsidiary hypothesis: The level of human capital with the level of costumer's capital in the hospitals has positive and significant relationship.

Fifth subsidiary hypothesis: The level of human capital with the level of structural capital in the hospitals has positive and significant relationship.

Sixth subsidiary hypothesis: The level of structural capital with the level of customer capital in the hospitals has positive and significant relationship.

Seventh subsidiary hypothesis: There is a significant positive relationship, between human capital and structural capital clients in hospitals.

\section{RESEARCH METHODS}

This study has analytical-descriptive function and practical purpose that uses reasonable sample to generalize the results and findings to the entire statistical community.

\section{Method of gathering information}

The main instrument for gathering data in this study is standard questionnaire (in terms of meaning and purpose) which is designed by Nick Bontis, a clear-sighted expert in intellectual capital, to measure the people's ideas about the current state of intellectual capital in organizations and in a lot of researches it has been set and benchmarked. In addition to reviews and notes the organizational documents, the study uses library studies.

\section{Statistical universe and sample}

The statistical universe of this research consists of all the heads, deputies and officials of administrative, financial and medical sections of hospitals which are related to Kermanshah University of Medical Sciences. In this study, whereas the universe is considered as the limit, so to calculate the needed sample size for the research Cochrane's Formula was used with limited sampling and the calculation formula is given in the following:

$$
n=\frac{N Z_{\frac{\alpha}{2}}{ }^{2} p(1-p)}{\varepsilon^{2}(N-1)+Z_{\frac{\alpha}{2}}{ }^{2} p(1-p)}
$$

In which: $P$ : estimated ratio of variable attributes; $P=5 / 0$, $Z$ : unit normal variable corresponding 95 percent confidence level; $Z_{\frac{\alpha}{2}}=1 / 96, \quad \mathcal{E}:$ The amount of allowable error based on the same research with five hundredth intended; $\mathcal{E}=0 / 05 ; \mathrm{n}=195$.

\section{Method to analyze data and test hypotheses}

For the analysis of data, descriptive and inferential methods are used. To test hypotheses, software SPSS (and parameters such as mean, variance, frequency, standard deviation and average test) and multiple regressions are used (Azar et al., 2002).

\section{THE RESULTS OF RESEARCH HYPOTHESES}

\section{First subsidiary hypothesis}

There is a significant positive relationship between the level of human capital in the hospitals and their performance. The results of Pearson's correlation test show that the correlation coefficient between the variable of human capital and organizational function in hospitals equals 0.389 (probability of $0.01>p$ ) which represents a moderate and positive relationship between them. It means that with the increase of human capital, the rates of organizational function will increase. Conversely, if you improve organizational function, human capital also improves. The findings of this study, regarding the mentioned hypothesis, have affinity with findings by Yazdani (1385), Williams (2001), Sofiian et al. (2003), Fayrr and Williams (2003), Wang and Chang (2005), Bontis (2000), 
Tan et al. (2007), Lim and Dalimore (2004) and Chen et al. (2004).

\section{Second subsidiary hypothesis}

There is a significant positive relationship between the level of structural capital in the hospitals and their performance. The results of Pearson's correlation test show that the correlation coefficient between the variable of structural capital and organizational function in hospitals equals 0.373 (probability of $0.01>p$ ) which represents a moderate and positive relationship between them. It means that with the increase of structural capital, the rates of organizational function will increase. Conversely, if you improve organizational function, structural capital also improved. Because the correlation analysis does not refer to the direction and cause and effect relationship, the results of regression analysis, by considering the structural capital variables as independent and organizational function as dependent, shows that about $37 \%$ of the changes in organizational function of hospitals can be attributed to the changes in the structural capital variables. The findings of this study, regarding the mentioned hypothesis, have affinity with findings by Yazdani (1385), Wang and Chang (2005), Bontis et al. (2000) and Chen et al. (2004).

\section{Third subsidiary hypothesis}

There is a significant positive relationship between the level of customer capital in the hospitals and their performance. The results of Pearson's correlation test show that the correlation coefficient between the variable of consumer's capital and organizational function in hospitals equals 0.448 (probability of $0.01>p$ ) which represents a moderate and positive relationship between them. It means that with the increase of consumer's capital, the rates of organizational function will increase. Conversely, if you improve organizational function, customer capital also improve. Because the correlation analysis does not refer to the direction and cause and effect relationship, the results of regression analysis, by considering the consumer's capital variables as independent and organizational function as dependent, shows that about $45 \%$ of the changes in organizational function of hospitals can be attributed to the changes in the consumer's capital variables.. The findings of this study, regarding the mentioned hypothesis, have affinity with findings by Yazdani (1385), Wang and Chang (2005), Bontis et al. (2000) and Chen et al. (2004).

\section{Fourth subsidiary hypothesis}

The level of human capital with the level of costumer's capital in the hospitals has positive and significant relationship.
The results of Pearson's correlation test show that there is a strong direct and positive relationship, with the size of 0.846 (probability of $0.01>p$ ) between human capital and consumer's capital in hospitals. The findings of this study, regarding the mentioned hypothesis, have affinity with findings by Yazdani (1385), Wang and Chang (2005), Bontis et al. (2000) and Chen et al. (2004).

\section{Fifth subsidiary hypothesis}

The level of human capital with the level of structural capital in the hospitals has positive and significant relationship. The results of Pearson's correlation test show that there is a strong direct and positive relationship, with the size of 0.841 (probability of $0.01>p$ ) between human capital and structural capital in hospitals. The findings of this study, regarding the mentioned hypothesis, have affinity with findings by Yazdani (1385), Wang and Chang (2005), Bontis et al. (2000) and Chen et al. (2004).

\section{Sixth subsidiary hypothesis}

The level of structural capital with the level of customer capital in the hospitals has positive and significant relationship. The results of Pearson's correlation test show that there is a strong direct and positive relationship, with the size of 0.819 (probability of $0.01>p$ ) between customer capital and structural capital in hospitals. The findings of this study, regarding the mentioned hypothesis, have affinity with findings by Yazdani (1385), Bontis et al. (2000) and Chen et al. (2004).

\section{Seventh subsidiary hypothesis}

There is a significant positive relationship, between human capital and structural capital clients in hospitals. The results of Pearson's correlation test show that there is a strong direct and positive relationship, with the size of 0.867 (probability of $0.01>p$ ), between human capital and structural customer capital in hospitals. The findings of this study, regarding the mentioned hypothesis, have affinity with findings by Yazdani (1385), Fayrr and Williams (2003), Wang and Chang (2005), Bontis (2000) and Tan et al. (2007), Lim and Dalimore (2004) and Chen et al. (2004).

\section{First major hypothesis}

The triple components of intellectual capital have a positive and meaningful effect on the performance of hospital. The results of regression analysis show that multiple correlation coefficient among the components of 
intellectual capital and organizational function in hospital equals 0.423 . In this way, $42 \%$ of the changes in organizational function have been resulted from the changes in intellectual capital and its components. In addition, other principles except intellectual capital affect on the hospitals related to the universities of Kermanshah province. It is in contrast with researches which think intellectual capital determines $80 \%$ of organizational function.

\section{Second major hypothesis}

There is a positive and meaningful relation between the component of intellectual capital (human, structural, and customer). The results of statistical analysis illustrate that there is a strong, direct and meaningful relation between the components of intellectual capital. Meanwhile, the highest degree of mutual relation is between consumer capital and human capital (0.846) and between structural capital and human capital (0841).

\section{Conclusion}

Intellectual capital as information science is a specific subjective experience that organizations can use to create wealth for themselves. In addition, this capital can be considered as a combination of non-tangible assets that do not appear on the balance sheet. If they managed in a good way, the organizations are able to gain competitive advantage in their markets. On this basis, customer oriented and market-oriented organization will create effective organizational procedures and processes that provide a good service to customers. The relationship between customer capital and structural capital leads to more business function and also improves trade function. At the end, it can be said that current research findings confirm this relationship.

\section{REFERENCES}

Azar A, Momeni M (2002). Statistics and its Application in Management (Statistical Analysis).Tehran: SAMT publication, Vol. 1

Alam GM, Khalifa MTB (2009). The impact of introducing a business marketing approach to education: a study on private $\mathrm{HE}$ in Bangladesh. Afr. J. Bus. Manage., 3 (9): 463-474.
Alam, GM, Hoque KE, Oloruntegbe, KO (2010). Quest for a better operation system in Education: Privatization, Teacher Educationalization or Voucherilization: glimpsing from consumer and product perspectives, Afr. J. Bus. Manage., 4(6):1202-1214

Alam GM, Hoque KE, Rout GK, Priyadarshani N (2010). Who gains from EFA - State Business of Education or Private Higher Education Business in Developing Nation: A study to understand the policy impact in Bangladesh? Afr. J. Bus. Manage., 4(5): 770-789

Alam GM, Hoque KE (2010). Who gains from "Brain and Body Drain" Business -Developing/developed world or individuals: A comparative study between skilled and semi/unskilled emigrants, Afr. J. Bus. Manage., 4(4): 534-548

Alam GM, Hoque KE, Ismail L, Mishra PK (2010). Do developing countries need education laws to manage its system or are ethics and a market-driven approach sufficient? Afr. J. Bus. Manage., 4(15): 3406-3416

Bontis N (1999). Managing organizational knowledge by diagnosing intellectual capital: framing and advancing the state of the field, Int. $\mathrm{J}$ Technol. Manage., 18( 5-8) : 433-62.

Brooking A (1997). Management of intellectual capital. Long Range Plann., 30(3): 364-5.

Bontis N, Chua W, Richardson S (2000). Intellectual capital and the nature of business in Malaysia. J. Intellect. Capital, 1 (1): 85-100.

Chatzkel J (2003). "The collapse of Enron and Role of Capita". J. Intellect. Capital, 4(2): 127-143.

Chatzkel J (2002). intellectual Capital > Capstone, Mankato, MN

Chen J, Zhu Z, Xie HY (2004). Measuring intellectual capital: a new model and empirical study. J. Intellect. Capital, 5: 195-212.

Davenport TH, Prusak L (1998). Working Knowledge: How Organizations Manage What They Know . Harvard Business School Press, Boston, MA.

Danaee FH (2007). Challenges for Public Administration in Iran. Tehran: SAMT publication. Unit seven: Knowledge-based Economy.

Edvinsson L, Malone M (1997). Intellectual Capital-Realizing Your Company's True Value by Finding Its Hidden Roots. Harper Business, New York, NY.

Halim S (2010). Statistical analysis on the intellectual capital statement. J. Intellect. Capital, 11(1): 61-73

Harrison S, Sullivan P (2000). Profiting from intellectual capital: learning from leading companies. J. Intellect. Capital, 1(1): 33-46.

Lev B (2001). "Intangibles: Management Measurement and Reporting", Brookings Institution Press, Washington, DC.

Marr B, Moustaghfir K (2005). Defining intellectual capital: a threedimensional approach". Manage. Decis., 43(9): 1114-28.

Roos G, Roos J (1997). Measuring your company's intellectual function. Long Range Plan., 30(3):413-26.

Stewart TA (1997). "Intellectual Capital: The New Wealth of Organizations", Doubleday, New York, NY.

Tovstiga G, Tulugurova E (2009). Intellectual capital practices: a fourregion comparative study. J. Intellect. Capital, 10 (1):70-80.

Zahedi M, Lotfizadeh F (2007). Dimensions and models to measure intellectual capital. J. Manage. Stud., 1 (12) 